\title{
Why should we monitor for hematologic adverse drug reactions to oxcarbazepine?
}

\author{
Gwang Cheon Jang, MD, PhD \\ Department of Pediatrics, National Health Insurance Service Ilsan Hospital, Goyang, Korea
}

Adverse drug reaction (ADRs) are unwanted effects of drug administration regardless of etiology and pathogenic mechanism. ADRs occur in about 10\%-20\% of all hospitalized patients and involve various mechanisms. Delayed type ADRs may appear after several months. Thus, periodic follow-up examinations are necessary. ${ }^{1)}$

According to the report of Korea Institute of Drug Safety \& Risk Management (KIDS) in 2015, antiepileptic drugs (AEDs) account for 2.2\% of total drugs causing ADRs ranging from nausea to skin rash to death. Leukopenia caused 2,562 of 112,418 cases (0.9\%), while neutropenia caused 2,303 cases (0.8\%). Among ADRs in AEDs, hematologic disorders range from thrombocytopenia or neutropenia to bone marrow failure. ${ }^{2,3)}$

Several hypotheses have been proposed to explain the mechanisms of ADRs, including direct toxicity, immune complexes, hapten formation, inhibition of colony forming units in bone marrow, complement-mediated mechanisms, and association with human leukocyte antigen (HLA). HLA-B*15:02 is significantly associated with oxcarbazepine (OXC)-induced Stevens-Johnson syndrome in Asian populations (Chinese and Thai). In Korean patients, OXC-induced maculopapular eruptions are significantly associated with HLA-B*40:02 and HLA-DQB 1*04:03, whereas HLA-B*15:01 is a protective allele. The mechanisms of druginduced neutropenia are not yet fully understood. Prolonged exposure to drugs affects the microenvironment of the bone marrow or the myeloid precursors. The metabolic pathways that metabolize drugs and chemicals are regulated by genetic factors. ${ }^{3-5)}$

The neutropenic patient (absolute neutrophil count [ANC], 1,500 cells $/ \mathrm{mm}^{3}$ ) is highly susceptible to bacterial, fungal, and viral infections, with the risk of infection associated with neutropenia grade and duration, while patients with grade IV neutropenia (ANC, 500 cells/mm³) are at a greater risk of infection regardless of the duration. Previous studies reported hematological side effects of carbamazepine (CBZ) at a frequency of 1:38,000-1:10,800, whereas ADRs of OXC are reportedly rare. OXC is used to treat partial and secondarily generalized tonicclonic seizures, and its active metabolite, monohydroxy derivative, exerts its effects on sodium channels and possibly potassium and calcium channels with a mechanism of action similar to that of CBZ and comparable efficacy but superior safety. ${ }^{6-9)}$

According to the KIDS report, there were 212 cases of OXC-induced ADRs in patients under 18 years of age between 2011 and 2015, including 3 cases (1.4\%) of hematologic side effect, 1 case of leukopenia, 1 case of neutropenia, and 1 case of thrombocytopenia. However, cases of OXC-induced side effects are possibly underestimated., ${ }^{2,3)}$

In the current issue of the Korean Journal of Pediatrics, Jung and Yoo ${ }^{10)}$ evaluated the hematologic profile of 184 patients treated with OXC. Hematologic side effects developed in 10 of the 184 patients (5.4\%) who were prescribed OXC between 2001 and 2018. Although the study was limited by its a single-center design, retrospective nature, and small number of cases, the 5.4\% frequency of hematologic side effects of OXC indicates that they are not rare; in fact, this rate is actually higher than previous data suggested. These data provide the basis for the need for careful follow-up of patients treated with OXC.
Corresponding author: Gwang Cheon Jang, MD, $\mathrm{PhD}$

Department of Pediatrics, National Health Insurance Service Ilsan Hospital, 100 Ilsan-ro, Ilsandong-gu, Goyang 10444, Korea

Tel: +82-31-900-0520

Fax: +82-31-900-0343

E-mail: janggwangc@yuhs.ac

https://orcid.org0000-0002-2423-9951

Received: 15 May, 2019

Accepted: 22 June, 2019
Copyright (C) 2019 by The Korean Pediatric Society

This is an open-access article distributed under the terms of the Creative Commons Attribution NonCommercial License (http://creativecommons.org/ licenses/by-nc/4.0/) which permits unrestricted noncommercial use, distribution, and reproduction in any medium, provided the original work is properly cited. 


\section{Conflicts of interest}

No potential conflicts of interest relevant to this article was reported.

\section{References}

1. Gomes ER, Demoly P. Epidemiology of hypersensitivity drug reactions. Curr Opin Allergy Clin Immunol 2005;5:309-16.

2. Trends in safety information reporting including medicines 2015 [Internet]. Anyang (Korea): Korea Institute of Drug Safety \& Risk Management; 2015 [cited 2019 Jun 28]. Available from: https://www. drugsafe.or.kr/iwt/ds/ko/bbs/EgovBbs.do?bbsId=BBSMSTR_0000000 00021\&nttId=1905\&pageIndex $=1 \&$ searchCnd $=\&$ searchWrd $=$.

3. Jang GC, Lim HS, Lee CJ. Epidemiology of pediatric adverse drug reactions in Korea: using big data of 48.1 million south Korean healthcare records and Korea adverse event reporting system database. In:
European Academy of Allergy and Clinical Immunology Congress; 2017 Jun 17-21; Helsinki, Finland.

4. Chen CB, Hsiao YH, Wu T, Hsih MS, Tassaneeyakul W, Jorns TP, et al. Risk and association of HLA with oxcarbazepine-induced cutaneous adverse reactions in Asians. Neurology 2017;88:78-86.

5. Moon J, Kim TJ, Lim JA, Sunwoo JS, Byun JI, Lee ST, et al. HLA$B * 40: 02$ and DRB 1*04:03 are risk factors for oxcarbazepine-induced maculopapular eruption. Epilepsia 2016;57:1879-86.

6. Verrotti A, Scaparrotta A, Grosso S, Chiarelli F, Coppola G. Anticonvulsant drugs and hematological disease. Neurol Sci 2014;35:983-93.

7. Tecoma ES. Oxcarbazepine. Epilepsia 1999;40 Suppl 5:S37-46.

8. Mahmud J, Mathews M, Verma S, Basil B. Oxcarbazepine-induced thrombocytopenia. Psychosomatics 2006;47:73-4.

9. Calamaras MR, Stowe ZN, Newport DJ. Pancytopenia associated with the introduction of oxcarbazepine. J Clin Psychopharmacol 2007;27: 217-8.

10. Jung GH, You SJ. Evaluation of hematologic profile may be needed for patients treated with oxcarbazepine. Korean J Pediatr 2019;62: 312-6. 